\title{
Relationship between screen time and sleep among Finnish preschool children : results from the DAGIS study
}

\section{Hiltunen, Pauliina}

2021-01

Hiltunen, P , Leppanen , M H , Ray , C , Maatta , S, Vepsalainen , H , Koivusilta , L , Sajaniemi , N , Erkkola , M \& Roos , E 2021 , ' Relationship between screen time and sleep among Finnish preschool children : results from the DAGIS study ' , Sleep Medicine , vol. 77 , pp. 75-81 . https://doi.org/10.1016/j.sleep.2020.11.008

http://hdl.handle.net/10138/337952

https://doi.org/10.1016/j.sleep.2020.11.008

cc_by_nc_nd

acceptedVersion

Downloaded from Helda, University of Helsinki institutional repository.

This is an electronic reprint of the original article.

This reprint may differ from the original in pagination and typographic detail.

Please cite the original version. 


\section{Title}

Relationship between screen time and sleep among Finnish preschool children: results from the DAGIS study

\section{Authors}

Pauliina Hiltunen ${ }_{1,2}^{*}$, Marja H Leppänen ${ }_{1,3}$, Carola Ray ${ }_{1,2}$, Suvi Määttä1,4, Henna Vepsäläinen 2 , Leena Koivusilta5, Nina Sajaniemi 6,7 , Maijaliisa Erkkola2, Eva Roos1,2,3

${ }_{1}$ Folkhälsan Research Center, Topeliuksenkatu 20, 00250 Helsinki, Finland

2 Department of Food and Nutrition, Faculty of Agriculture and Forestry, University of Helsinki, Latokartanonkaari 7, P.O. Box 27, 00014 Helsinki, Finland

${ }_{3}$ Department of Public Health, Faculty of Medicine, P.O. Box 63, 00014 Helsinki, Finland

${ }_{4}$ Faculty of Social Sciences, University of Helsinki, Unioninkatu 37, P.O. Box 54, 00014 Helsinki, Finland

${ }_{5}$ Department of Social Research, University of Turku, FI-20014, Turku, Finland

${ }_{6}$ Faculty of Educational Sciences, University of Helsinki, Siltavuorenpenger 1-5, 10, P.O. Box 9, 00014 Helsinki, Finland

${ }_{7}$ Philosophical Faculty, School of Applied Educational Science and Teacher Education, University of Eastern Finland, P.O. Box 111, FI-8010, Joensuu, Finland

* Correspondence: pauliina.hiltunen@folkhalsan.fi, Topeliuksenkatu 20, 00250 Helsinki, Finland

E-mail addresses:

Pauliina Hiltunen: pauliina.hiltunen@folkhalsan.fi

Eva Roos: eva.roos@folkhalsan.fi 


\section{Abstract}

Study objectives: To examine the associations between screen time, the time used on different screen devices, and sleep in a sample of Finnish preschool children.

Methods: The current study analyzed cross-sectional data from the DAGIS study carried out in Finland in 2015-2016 on 736 children aged 3-6 years. Parents reported in a 7-day diary the durations the child used screen devices daily, with separate details about watching TV or DVDs, using tablets or smartphones, and using computers. In addition, parents reported children's bedtimes and wake-up times, which were further used in calculating sleep duration. Parents answered questions regarding their child's sleep consistency. Statistical analyses included adjusted general linear modeling.

Results: An hourly increase in total screen time was associated with a bedtime that was 11 minutes later $(\mathrm{p}<$ 0.001 ) and a shorter sleep duration of 10 minutes $(\mathrm{p}<0.001)$. More TV/DVD watching was associated with later bedtimes $(\mathrm{p}=0.016)$ and a shorter sleep duration $(\mathrm{p}=0.001)$. More smartphone/tablet use was associated with later bedtimes $(p=0.005)$, later wake-up times $(p=0.038)$, and weaker sleep consistency $(p=0.024)$. More computer use was associated with later bedtimes $(p=0.046)$. Results did not differ between genders.

Conclusions: Increased screen time was associated with later bedtimes and shorter sleep duration among preschool children. Adverse associations with sleep outcomes were found for each screen device. Attention should be paid to promoting balanced use of screens and regular sleep habits in young children.

Keywords: screen time, smartphones, tablets, computer use, sleep habits, children 


\section{Introduction}

The use of screen devices in everyday life is becoming more common even at a young age (Kabali et al. 2015). Excessive screen time has been recognized as a public health concern because it has been found to associate with increased risks of being obese (Engberg et al. 2019; Robinson et al. 2017), lower psychosocial wellbeing, and attention problems among children aged 3-5 years (Carson et al. 2015; Hinkley et al. 2014; LeBlanc et al. 2012). Insufficient sleep and irregular sleep habits in preschool children have been associated with obesity (Miller et al. 2015), behavioral problems (Séguin \& Klimek 2016; Wu et al. 2017), and compromised physical and mental health (Fukuda et al. 2019). Sufficient sleep and healthy sleep habits are crucial for healthy growth and development, especially in the early years (Dahl 2007).

Studies have shown associations between increased screen time and poor sleep outcomes, such as sleep disturbances (Brockmann et al. 2015; Paavonen et al. 2006) and irregular sleep habits in children under school age (Beyens \& Nathanson 2019; Genuneit et al. 2017). Previous studies have investigated whether screen time affects sleep by reducing sleep duration (a sleep displacement process) or by shifting both bedtimes and wakeup times later, resulting in a delayed circadian rhythm (a sleep time shifting process). Some studies have reported that screen time is associated with reduced sleep duration in preschool children (Paavonen et al 2006; Przybylski 2019; Séguin \& Klimek et al. 2016). In addition, Belmon et al. (2019) found moderate evidence for screen time as a determinant for decreased sleep duration in the age group of 4-12 in their review of longitudinal studies. However, not all studies have confirmed this finding. The cross-sectional study by Hense et al. (2011) found no clear evidence for decreased sleep duration. In contrast, Beyens's and Nathanson's (2019) study suggested that, instead of decreasing sleep duration, screen time shifts bedtimes and wake-up times later in preschool children. Nonetheless, Moorman's (2019) review was supposedly the first review concerning screen time and sleep among preschool children and concluded that screen time negatively impacts sleep outcomes, such as sleep duration and bedtimes.

Screen time can affect sleep through several mechanisms (Cain \& Gradisar 2010). Using screens in the evening has been found to be a specific risk factor for sleep problems, because screen time can cause delay of the circadian rhythm (Garrison et al. 2011; Moorman et al. 2019). Delay of the circadian rhythm can be caused because exposure to blue light in the evening disrupts melatonin production (Exelmans \& Van den Bulck 2019). Also stimulating content of the screens can delay sleep onset latency, due to increased psychophysiological arousal and activation of the autonomic nervous system (Cain \& Gradisar 2010). In addition, screen time can postpone going to bed, because it is time-consuming, and can also replace soothing bedtime rituals (Cain \& Gradisar 2010; Garrison et al. 2011). Using screens in the bedroom has been found to be associated with sleep problems (Garrison et al. 2011) due to the conditioned learning effect between screen 
time and bedroom (Hauri \& Fisher 1986). Among young adults, prolonged screen time has been observed to cause physical discomfort, which results in sleep problems (Thomee et al. 2010).

Review by Moorman (2019) revealed the lack of studies concerning smartphone and tablet use, as the majority of review studies included TV and computer use, but only a scatter of studies also included smartphone or tablet use. Studies have mostly used questions directed to parents to estimate children's screen time and sleep habits on a weekly average, and there is a need for more accurate screening methods such as time diaries (Beyens \& Nathanson 2019). As the use of all kinds of screen devices is becoming more common in young children, more information is needed on accurate methods to analyze how screen time and the use of screen devices, including smartphones and tablets, are associated with sleep habits in young children.

This study aims to examine the association between screen time and sleep habits in a sample of Finnish preschool children. The research questions are: 1) Is the amount of screen time associated with bedtimes, wake-up times, sleep duration, and sleep consistency in preschool children (analyzed separately for total, weekday, and weekend)?; and 2) Is there an independent association of the use of each screen device (TV, computer, smartphones, or tablets) with sleep habits? In addition, we examine whether the studied associations differ between genders.

\section{Methods}

\subsection{Participants and study design}

The detailed DAGIS study protocol and the survey design have been published previously (Määttä 2015; Lehto et al. 2018). A cross-sectional study was conducted between September 2015 and April 2016 as part of the larger DAGIS (Increased Health and Wellbeing in Preschools) research project, investigating health behaviors and aiming to diminish socioeconomic differences in preschool children's energy balance-related behaviors. Participants were recruited in eight municipalities, through 66 preschools in Southern and Western Finland. All families with a preschool child aged 3-6 years were invited to the study by an informational letter through the preschools. The overall response rate among invited participants was $25 \%$. Flow chart is presented in a separate study by Lehto et al (2018). The parents gave their written informed consent. In the current study, the sample contained 736 preschool children and their parents, who had completed the required screen time and sleep habit data in a sedentary behavior diary (52\% boys; mean age 4.7; SD 0.89). The study was approved by the University of Helsinki Ethical Review Board in the Humanities and Social and Behavioral Sciences (\#6/2015). 


\subsection{Screen time}

Parents filled in the 7-day sedentary behavior diary in which they reported the number of times their child used screen devices daily and the duration of total use per day, with separate responses about: 1) watching TV, 2) watching DVDs or videos, 3) tablet or smartphone use, and 4) computer use or computer gaming. The diary used in this study was further modified for the Finnish context from the original validated diary by Wen et al. (2010). The screen time variable was the overall combination of the variables mentioned above and was analyzed as a continuous variable. The variable was analyzed separately in total (including $\geq 3$ weekdays and $\geq 1$ weekend days), on weekdays (including $\geq 3$ weekdays), and on weekend days (including $\geq 1$ weekend days).

The use of different screen devices was analyzed separately, with the exception that TV and DVD/video watching were combined as one variable. All variables were categorized by non-normal distributions. The TV/DVD/video watching and tablet/smartphone use variables were categorized as tertiles based on cut-points for three equal groups: lower, middle, or upper thirds. TV/DVD/video watching tertiles were: 0-42 min, 43$69 \mathrm{~min}$, and $\geq 70 \mathrm{~min} / \mathrm{day}$. Tablet/smartphone use groups were: $0 \mathrm{~min}, 1-14 \mathrm{~min}$, and $\geq 15 \mathrm{~min} / \mathrm{day}$. Computer use was dichotomized as non-users ( $0 \mathrm{~min} /$ day) and users ( $\geq 1 \mathrm{~min} /$ day $)$, as the majority of children $(71 \%)$ had no computer time.

\subsection{Sleep habits}

The term sleep habits used in this paper refers to bedtimes, wake-up times, sleep duration, and sleep consistency.

\subsubsection{Bedtimes, wake-up times, and sleep duration}

Parents reported their child's bedtimes and wake-up times in a 7-day sedentary behavior diary, and sleep duration was calculated from the reported variables. It was assumed that screen time during the day affects sleeping that night, so the weekday sleeping variables included Monday, Tuesday, Wednesday, Thursday, and Friday nights. The weekend sleeping variables included Saturday and Sunday nights, and consequently weekend wake-up time variable consisted of Sunday and Monday mornings. Data from at least three weekday nights plus one weekend night were required for bedtime, wake-up time, and sleep duration variables to include the participant in the study. Mean values for weekdays and weekend days were summed up for the total sleep duration mean: [(sleep duration on weekdays $\times 5)+($ sleep duration on weekend days $\times 2)] / 7$.

\subsubsection{Sleep consistency}

Parents reported in a separate questionnaire their child's sleep consistency, which referred to the regularity of sleep habits. Questions were based on the Children's Sleep Habits Questionnaire (Goodlin-Jones et al. 2008), and the following items were selected from the original questionnaire: How many times during the last typical 
week... "A. child went to bed at the same time each night?," "B. child slept the appropriate amount?," and "C. child slept about the same amount each night?" The answer categories were: not once, 1-2 times, 3-4 times, 5-6 times, or daily. The variables were used as a continuous (1-5). A sleep consistency sum variable was formed, consisting of variables A, B, and C (Cronbach's Alpha 0.693), because these variables measured consistency of sleep habits. The score was an average of these variables. A higher score referred to more consistent sleep habits.

\subsection{Covariates}

Parents reported their child's gender (boy, girl) and the highest educational level in the family. The family's educational level was categorized in three groups: low (high school/vocational school/comprehensive school), middle (bachelor's degree or equivalent), and high (master's degree or higher). The child's age was calculated from the parent-reported birth date. The hours at daycare were calculated from the parent-reported daycare hours in the 7-day sedentary behavior diary. The research season was the time the study was conducted and was categorized in three groups: September-October, November-December, January-April. We used the research season as a covariate because municipalities had different data collection weeks and because the length of daylight and the weather conditions can vary largely extent between seasons in Finland.

\subsection{Statistical analyses}

All variables were normally distributed. Descriptive information was presented using means and standard deviations or frequencies and percentages $(\%)$. Gender differences were analyzed for descriptive tables using t-tests for continuous variables and chi-square tests for categorized variables. We investigated if associations differed between boys and girls with interaction terms in the models. No interactions were found, and therefore, further results presented genders together. General linear modeling was used to regress how total screen time (total, weekdays, and weekends) was associated with bedtimes, wake-up times, and sleep duration in corresponding time periods and with sleep consistency. General linear modeling was also used to regress how the use of TV/DVDs (three categories), computers (two categories), and smartphones/tablets (three categories) were associated separately with total bedtimes, wake-up times, sleep duration, and sleep consistency. All analyses were adjusted for the child's age, child's gender, highest educational level in the family, research season and hours the child spent in daycare during the week. The level of significance of 5\% 
or less was used to indicate statistically significant findings. All statistical analyses were made using the SPSS statistical program version 25 (IBM, Armonk, NY, USA).

\section{Results}

Descriptive information, such as means for screen time and sleep habits, is given in Table 1, which includes all continuous variables. Total screen time was on average $76 \mathrm{~min} /$ day. Per weekday the mean screen time was $63 \mathrm{~min}$ and per weekend day $109 \mathrm{~min}$. Watching TV/DVDs and using smartphones/tablets was statistically significant greater on weekends, but such a difference was not found with computer use. Boys had statistically significant more computer time than girls $(\mathrm{p}=0.001)$ and woke up earlier than girls $(\mathrm{p}=0.003)$. Sleep consistency data were available for 736 children. Of the parents that filled in the questions measuring sleep consistency, $88 \%(\mathrm{~N}=645)$ were mothers.

Table 1. Descriptive characteristics of the participating Finnish children aged 3-6 (continuous variables).

\begin{tabular}{|c|c|c|c|c|c|c|c|}
\hline & \multicolumn{2}{|l|}{ All } & \multicolumn{2}{|l|}{ Girls } & \multicolumn{2}{|c|}{ Boys } & \multirow{2}{*}{$\begin{array}{l}\text { P-value for gender difference } \\
\text { (t-test) }\end{array}$} \\
\hline & $\overline{\mathbf{N}}$ & Mean \pm SD & $\mathbf{N}$ & Mean \pm SD & $\mathbf{N}$ & Mean \pm SD & \\
\hline$\overline{\text { Age (years) }}$ & 736 & $4.7 \pm 0.9$ & 355 & $4.7 \pm 0.9$ & 381 & $4.8 \pm 0.9$ & 0.47 \\
\hline Total hours in daycare during week (hours) & 736 & $24.9 \pm 8.3$ & 355 & $24.1 \pm 8.5$ & 381 & $25.7 \pm 8.0$ & 0.012 \\
\hline \multicolumn{8}{|l|}{ Screen time variables } \\
\hline \multicolumn{8}{|l|}{ Screen time (overall) (min/day) } \\
\hline total & 736 & $75.9 \pm 36.6$ & 355 & $74.6 \pm 35.7$ & 381 & $77.1 \pm 37.5$ & 0.36 \\
\hline weekday & 736 & $62.5 \pm 33.4$ & 355 & $62.0 \pm 31.0$ & 381 & $63.0 \pm 35.4$ & 0.67 \\
\hline weekend & 736 & $109.2 \pm 62.8$ & 355 & $106.1 \pm 63.4$ & 381 & $112.1 \pm 62.2$ & 0.19 \\
\hline \multicolumn{8}{|l|}{ TV/DVD time ( $\mathrm{min} /$ day) } \\
\hline total & 696 & $59.0 \pm 30.6$ & 335 & $59.2 \pm 31.4$ & 361 & $58.8 \pm 29.9$ & 0.87 \\
\hline weekday & 720 & $49.2 \pm 28.1$ & 345 & $50.1 \pm 28.6$ & 375 & $48.4 \pm 27.7$ & 0.41 \\
\hline weekend & 699 & $85.1 \pm 54.5$ & 337 & $83.8 \pm 56.0$ & 362 & $86.3 \pm 53.1$ & 0.55 \\
\hline \multicolumn{8}{|l|}{ Tablet/smartphone time (min/day) } \\
\hline total & 712 & $14.5 \pm 20.7$ & 343 & $14.3 \pm 20.7$ & 369 & $14.6 \pm 20.7$ & 0.88 \\
\hline weekday & 727 & $12.2 \pm 19.2$ & 349 & $12.1 \pm 19.0$ & 378 & $12.3 \pm 19.4$ & 0.89 \\
\hline weekend & 716 & $20.3 \pm 30.8$ & 347 & $20.1 \pm 30.9$ & 369 & $20.6 \pm 30.7$ & 0.83 \\
\hline \multicolumn{8}{|l|}{ Computer time (min/day) } \\
\hline total & 691 & $4.7 \pm 13.1$ & 332 & $3.0 \pm 8.0$ & 359 & $6.2 \pm 16.3$ & 0.001 \\
\hline weekday & 711 & $3.9 \pm 12.4$ & 341 & $2.5 \pm 8.4$ & 370 & $5.2 \pm 15.1$ & 0.003 \\
\hline weekend & 691 & $7.3 \pm 21.1$ & 332 & $5.3 \pm 15.9$ & 359 & $9.2 \pm 24.9$ & 0.014 \\
\hline \multicolumn{8}{|l|}{ Sleep variables } \\
\hline \multicolumn{8}{|l|}{ Bedtime (hours) } \\
\hline total & 728 & $20.9 \pm 0.6$ & 352 & $20.9 \pm 0.6$ & 376 & $20.9 \pm 0.6$ & 0.35 \\
\hline weekday & 736 & $20.8 \pm 0.6$ & 355 & $20.9 \pm 0.6$ & 381 & $20.8 \pm 0.6$ & 0.34 \\
\hline weekend & 728 & $21.0 \pm 0.8$ & 352 & $21.0 \pm 0.9$ & 376 & $21.0 \pm 0.7$ & 0.46 \\
\hline \multicolumn{8}{|l|}{ Wake-up time (hours) } \\
\hline total & 734 & $7.3 \pm 0.5$ & 353 & $7.3 \pm 0.6$ & 381 & $7.2 \pm 0.5$ & 0.003 \\
\hline weekday & 736 & $7.2 \pm 0.5$ & 355 & $7.2 \pm 0.6$ & 381 & $7.1 \pm 0.5$ & 0.002 \\
\hline weekend & 734 & $7.4 \pm 0.7$ & 353 & $7.5 \pm 0.7$ & 381 & $7.4 \pm 0.7$ & 0.021 \\
\hline \multicolumn{8}{|l|}{ Sleep duration (hours/night) } \\
\hline total & 725 & $10.4 \pm 0.6$ & 351 & $10.4 \pm 0.6$ & 374 & $10.3 \pm 0.6$ & 0.13 \\
\hline weekday & 736 & $10.3 \pm 0.6$ & 355 & $10.4 \pm 0.6$ & 381 & $10.3 \pm 0.6$ & 0.13 \\
\hline weekend & 725 & $10.5 \pm 0.7$ & 351 & $10.5 \pm 0.7$ & 374 & $10.4 \pm 0.7$ & $\overline{0} 0.21$ \\
\hline Sleep consistency $(1-5)$ & 736 & $4.3 \pm 0.6$ & 355 & $4.2 \pm 0.6$ & 381 & $4.3 \pm 0.6$ & 0.22 \\
\hline
\end{tabular}

Statistically significant results are bolded. SD = Standard deviation 
The educational level of the family was distributed in the following way: high education (master's degree or higher) was $36 \%$, middle education (bachelor's degree or equivalent) was $43 \%$, and low education (high school/vocational school/comprehensive school) was $21 \%$. The majority of the children (72\%) were $4-5$ years old and the study was conducted between September-December for the majority of the children (80\%). TV/DVD watching was the most common, and in the upper tertile children watched 70 minutes or more TV/DVDs per day, whereas smartphone/tablet use in the upper tertile was 15 minutes or more per day. Further descriptive information about the categorized variables are presented in Table 2.

Table 2. Descriptive characteristics of the participating Finnish children aged 3-6 (categorized variables).

\begin{tabular}{|c|c|c|c|c|}
\hline & All $(N=736)$ & $\begin{array}{l}\text { Girls } \\
(\mathbf{N}=355)\end{array}$ & $\begin{array}{l}\text { Boys } \\
(\mathrm{N}=381)\end{array}$ & $\begin{array}{l}\text { P-value for } \\
\text { gender } \\
\text { difference }\end{array}$ \\
\hline & $\%(\mathrm{~N})$ & $\%(\mathrm{~N})$ & $\%(\mathbf{N})$ & $(\chi 2$-test $)$ \\
\hline Highest family educational level* & & & & 0.14 \\
\hline Low education & $21(154)$ & $21(76)$ & $20(178)$ & \\
\hline Middle education & $43(313)$ & $46(161)$ & $40(152)$ & \\
\hline High education & $36(266)$ & $33(115)$ & $40(151)$ & \\
\hline \multicolumn{5}{|l|}{ Child's age } \\
\hline 3 years & $21(157)$ & $23(80)$ & $29(77)$ & 0.89 \\
\hline 4 years & $36(261)$ & $34(121)$ & $37(140)$ & \\
\hline 5 years & $36(262)$ & $35(125)$ & $36(137)$ & \\
\hline 6 years & $8(56)$ & $8(29)$ & $7(137)$ & \\
\hline \multicolumn{5}{|l|}{ Research season } \\
\hline September-October & $44(322)$ & $43(154)$ & $44(168)$ & 0.60 \\
\hline November-December & $36(263)$ & $35(124)$ & 37 (139) & \\
\hline January-April & $20(151)$ & $22(77)$ & $19(74)$ & \\
\hline TV/DVD/video time total & & & & 0.24 \\
\hline$<43 \mathrm{~min} /$ day & $33(232)$ & $36(122)$ & $31(110)$ & \\
\hline 43-69 $\mathrm{min} /$ day & $34(235)$ & $31(105)$ & $36(130)$ & \\
\hline$\geq 70 \mathrm{~min} /$ day & $33(229)$ & $32(108)$ & $34(121)$ & \\
\hline Smartphone/tablet time total & & & & 0.39 \\
\hline $0 \mathrm{~min} /$ day & $36(251)$ & $38(129)$ & $33(122)$ & \\
\hline $1-14 \mathrm{~min} /$ day & $32(225)$ & $30(102)$ & $34(123)$ & \\
\hline$\geq 15 \mathrm{~min} /$ day & $33(231)$ & $32(110)$ & $33(121)$ & \\
\hline Computer time total & & & & 0.064 \\
\hline no computer time & $71(489)$ & $74(246)$ & $68(243)$ & \\
\hline had computer time & $29(202)$ & $26(86)$ & $32(116)$ & \\
\hline
\end{tabular}

*low = high school/vocational school/comprehensive school,

middle $=$ bachelor's degree or equivalent, and high $=$ master's degree or higher. 


\section{$2 \quad 3.1$ Associations between screen time and sleep habits}

3 Table 3 shows the adjusted associations between screen time and sleep habits. All analyses were adjusted for the child's age, child's gender, highest educational level in the family, research season and hours the child spent in daycare during the week. Statistically significant associations were found between total screen time and later bedtimes (coefficient $b=0.18, p<0.001)$ and shorter sleep duration $(b=-0.16, p<0.001)$. To contextualize these effect sizes, every hour of total screen time was associated with a bedtime that was 11 minutes later and a shorter sleep duration of 10 minutes. The same associations were observed on weekdays and on weekend days. We found no associations between screen time and wake-up times or sleep consistency.

Table 3. Associations between screen time and sleep habits among Finnish preschool children aged 3-6.

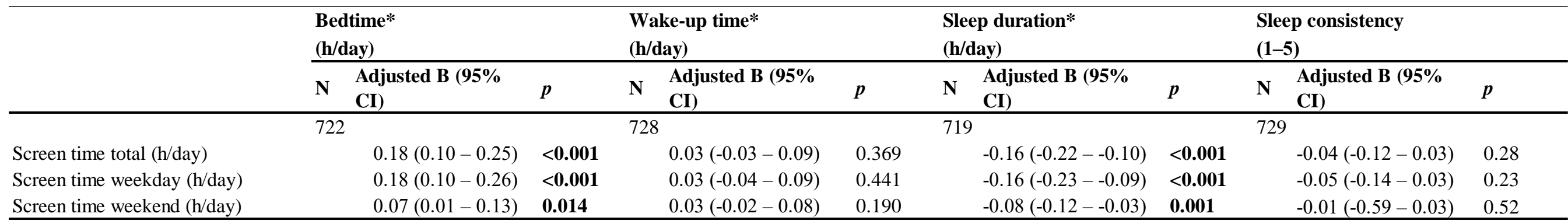

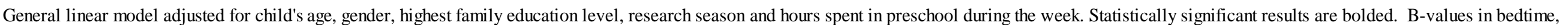




\subsection{Associations between the use of different screen devices and sleep habits}

Table 4 shows the adjusted associations between the use of different screen devices and sleep habits. Children in the upper tertile of watching TV/DVDs per day ( $\geq 70 \mathrm{~min} /$ day) went to bed 8 minutes later $(b=0.14, p=0.016)$ and had a shorter sleep duration by 10 minutes $(b=-0.16, p=0.001)$ compared to children in the lower tertile ( $<43 \mathrm{~min} /$ day). Children with 15 minutes or more of daily tablet/smartphone use went to bed 10 minutes later $(b=0.15$, $p=0.005)$, had weaker sleep consistency $(b=-0.13, p=0.024)$, and woke up 5 minutes later $(b=0.09 p=0.04)$ than children with no daily tablet/smartphone use. Children with computer use $(\geq 1 \mathrm{~min} /$ day $)$ went to bed 6 minutes later $(b=0.10, p=0.046)$ compared to children with no computer use.

Table 4. The associations between the use of screen devices and sleep habits among Finnish preschool children aged 3-6.

\begin{tabular}{|c|c|c|c|c|c|c|c|c|c|c|c|c|}
\hline & $\begin{array}{l}\text { Bedt } \\
(\mathrm{h} / \mathrm{d} \mathbf{e}\end{array}$ & ne total & & $\begin{array}{l}\text { Wake } \\
\text { (h/da }\end{array}$ & $\begin{array}{l}\text { y) } \\
\text { yp time total }\end{array}$ & & $\begin{array}{l}\text { Sleer } \\
(\mathrm{h} / \mathrm{da}\end{array}$ & $\begin{array}{l}\text { duration total } \\
\text { y) }\end{array}$ & & $\begin{array}{l}\text { Sleep } \\
(1-5) \\
\end{array}$ & consistency & \\
\hline & $\mathbf{N}$ & $\begin{array}{c}\text { Adjusted B (95\% } \\
\text { CI) }\end{array}$ & $p$ & $\mathbf{N}$ & $\begin{array}{c}\text { Adjusted B (95\% } \\
\text { CI) }\end{array}$ & $p$ & $\mathbf{N}$ & $\begin{array}{c}\text { Adjusted B (95\% } \\
\text { CI) }\end{array}$ & $p$ & $\mathbf{N}$ & $\begin{array}{c}\text { Adjusted B (95\% } \\
\text { CI) }\end{array}$ & $p$ \\
\hline the lower tertile (total use $<43 \mathrm{~min} /$ day) & & $0^{\mathrm{a}}$ & . & & $0^{\mathrm{a}}$ & . & & $0^{\mathrm{a}}$ & . & & $0^{\mathrm{a}}$ & . \\
\hline the middle tertile (total use $43-69 \mathrm{~min} /$ day) & & $0.04(-0.07-0.15)$ & 0.48 & & $-0.03(-0.12-0.07)$ & 0.58 & & $-0.10(-0.19--0.05)$ & 0.038 & & $-0.03(-0.14-0.09)$ & 0.62 \\
\hline the upper tertile (total use $\geq 70 \mathrm{~min} /$ day) & & $0.14(0.03-0.25)$ & 0.016 & & $-0.004(-0.09-0.10)$ & 0.94 & & $-0.16(-0.25--0.07)$ & 0.001 & & $-0.03(-0.15-0.08)$ & 0.58 \\
\hline Smartphone/tablet use total & 694 & & & 700 & & & 691 & & & 701 & & \\
\hline the lower tertile (total use $0 \mathrm{~min}$ ) & & $0^{\mathrm{a}}$ & . & & $0^{\mathrm{a}}$ & . & & $0^{\mathrm{a}}$ & . & & $0^{\mathrm{a}}$ & . \\
\hline the middle tertile (total use $1-14 \mathrm{~min} /$ day) & & $0.05(-0.06-0.16)$ & 0.37 & & $0.05(-0.04-0.14)$ & 0.29 & & $-0.01(-0.09-0.10)$ & 0.89 & & $-0.10(-0.21-0.02)$ & 0.08 \\
\hline the upper tertile (total use $\geq 15 \mathrm{~min} /$ day) & & $0.15(0.46-0.26)$ & 0.005 & & $0.09(0.005-0.18)$ & 0.038 & & $-0.08(-0.17-0.01)$ & 0.09 & & $-0.13(-0.24--0.02)$ & 0.024 \\
\hline$\underline{\text { Computer use total }}$ & 678 & & & 684 & & & 676 & & & 685 & & \\
\hline the non-users (total use $0 \mathrm{~min}$ ) & & $0^{\mathrm{a}}$ & . & & $0^{\mathrm{a}}$ & . & & $0^{\mathrm{a}}$ & . & & $0^{\mathrm{a}}$ & . \\
\hline the users ( $\geq 1 \mathrm{~min} /$ day) & & $0.10(0.002-0.21)$ & 0.046 & & $0.04(-0.04-0.13)$ & 0.33 & & $-0.07(-0.16-0.14)$ & 0.101 & & $-0.04(-0.14-0.07)$ & 0.50 \\
\hline
\end{tabular}

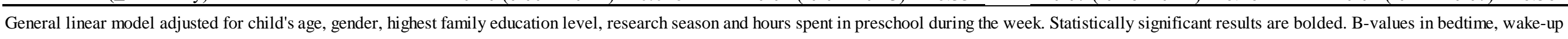

time, and sleep duration represent hours in decimals (hours in minutes $=\mathrm{B}$ x 60 ). ${ }^{\mathrm{a}}=$ reference value. $\mathrm{CI}=$ Confidence interval. 


\section{Discussion}

The aim of the current study was to investigate the relationship between screen time and sleep habits, as indicated with bedtimes, wake-up times, sleep duration, and sleep consistency in a sample of Finnish preschool-aged children. Results showed that the higher amount of total screen time was associated with later bedtimes and shorter sleep duration, on both weekdays and weekends, even after the potential confounding factors were controlled for. Results did not differ between genders.

Our results are in line with previous studies (Moorman et al. 2018; Paavonen et al 2006; Przybylski 2019; Séguin \& Klimek 2016) that suggest that screen time is associated with later bedtimes and shorter sleep duration in preschool children. Przybylski (2019) reported coincident delays in bedtimes among children aged 6 months to 5 years and Hale and Guan (2015) among older children. Delays in bedtimes and decreases in sleep duration were modest per hour but statistically significant. The magnitudes of these results can add up when children grow older as the amount of children's screen time increases with age (Vandewater et al. 2005). This is why the topic is important to study among younger children, when habits are formed. Results thus support the previous studies, showing that associations between screen time and sleep habits can be observed at a young age.

In this study, total screen time was not found to associate with wake-up times, which may support the displacement process rather than a delayed circadian rhythm. This supposition is debatable, as all participating children in this study were attending preschool. It might be that preschool children's wake-up times are determined by the parents' schedules and therefore more likely to be enforced rather than spontaneous. This may explain why total screen time was not found to be associated with wake-up times in this study sample. The results might have been different if the sample had included children in home care or other day care options. Future studies should collect data on whether wake-up time is enforced or spontaneous.

When analyzing screen devices separately, associations with at least one of the sleep outcomes (bedtimes, wake-up times, sleep duration, sleep consistency) were found for each screen device. All of the observed devices were associated with later bedtimes, in line with previous studies (Beyens \& Nathanson 2019). In addition to delays in bedtimes, TV/DVD watching was also associated with a shorter sleep duration, but smartphone/tablet use was instead associated with later wake-up times and weaker sleep consistency. Watching TV/DVDs was common and contributed the most to total screen time, whereas the use of a smartphone, tablet, or computer was less frequent and contributed less to total screen time. This explains why total screen time was associated with shorter sleep duration. It seems that different screen devices have slightly different associations with sleep habits. It might be that small portable devices such as smartphones and tablets 
are especially harmful to sleep consistency because they can be used in bed. Using smartphones or tablets for only 15 minutes was associated with worsening sleep outcomes.

Children's sleep and screen time habits are a result of a complex parent and child interactions (Lauricella et al. 2015), affected by various factors, such as family environment and parental characteristics and practices (Dubois-Comtois et al. 2019; Lauricella et al. 2015; Tang et al. 2018). It would be important to study how parental practices confound the associations between screen time and sleep behaviors. Parenting style and the amount of parental control (e.g. strict rules and routines) or permissiveness in a child's screen time and sleep behavior are not examined in this study, yet these factors cannot be underestimated when interpreting these results. This is especially important because sleep patterns in this study were parent-reported, instead of objectively measured. Operationalizing sleep duration as the time elapsed since parent-reported bedtime and wake-up time fails to detect sleep onset latency, which could be delayed due to difficulties falling asleep (Cain \& Gradisar, 2010). It also does not detect the time child spent in bed before deciding to try to sleep (shuteye latency), nor the time child was awake during the night (wake after sleep onset), which may be affected due to screen time (Cain \& Gradisar, 2010). Non-objective methods can detect less of the biological effect screen devices have on sleep and emphasize the influence of parental practices and routines related to sleep. In addition, as meeting the guidelines for sleep and/or physical activity have been associated with lower waist circumference and body mass index (Leppänen et al. 2019), there is a need for further studies investigating the potential role of parental practices related to these behaviors.

The strengths of this study include a sample of 736 children and daily screen time and sleep habit diaries that were filled in by the parents for 7 days. Diaries enable acquiring daily information about the use of different screen devices instead of parents having to think back about how the children behaved on average. Sleep habits were assessed not only with sleep duration, bedtimes, and wake-up times but also with parent-reported sleep consistency to gain more comprehensive data.

This study has several limitations. The sample in this study may be somewhat selected because of the low participation rate. It might be that parents who were already interested in and aware of healthy lifestyles agreed to participate, and because of this, the associations detected in this study may have been weaker than in the general population. The associations could have been stronger if the sample had not been that limited. Low participation rate is problematic for the generalizability of the results. It is also possible that being aware of the study would lead to demand characteristics (more favorable behaviors during the week) or to social desirability bias when filling in the sedentary behavior diary and questionnaire. The results may also have been influenced by the common method bias due to the cross-sectional data from one source. 
Among the limitations is that sleep duration was non-objectively measured. Also, we had no information about what time of the day the screens were used and no information about the screen time content (e.g. active education, gaming, passive entertainment), which is identified as an important predictive factor of sleeping problems (Garrison et al. 2011; Paavonen et al. 2006). Sleep consistency sum variable was assessed retrospectively by the parents, which could have led to recall errors. TV and smartphone use have shown to be associated with increased napping during the day (Beyens \& Nathanson 2019; Moorman 2019), but we did not study daytime napping or include napping time in the sleep duration.

Because the study was cross-sectional, the cause-and-effect relationship between screen time and sleep cannot be determined. However, screen time data were available for 7 days and sleeping data for those 7 nights. Screen time during the days was associated with later bedtimes and shorter sleep durations during the nights. Despite the limitations, it seems that screen time affects sleeping. Further research with objective methods is needed to gain knowledge about the impact of screen time on sleep in preschool children, and how parental practices confound these associations.

\section{Conclusions}

The results imply that a higher amount of screen time is associated with later bedtimes and shorter sleep duration during both weekdays and weekends among Finnish preschool children. Associations with the sleep outcomes were found for each screen device. Even a small amount of smartphone or tablet use was associated with worse sleep outcomes. Results did not differ between genders. These results highlight the need to pay attention to promoting balanced use of screens and regular sleep habits in young children.

\section{Acknowledgements}

The authors thank the preschools, the preschool personnel, and the parents for their participation in the DAGIS study and the research staff for data collection. The authors thank the collaborating partners of the DAGIS study for providing assistance in designing the DAGIS study. The authors also thank Rejane Figueiredo for being involved in the statistical analyses.

\section{Authors' contributions}

ER is the principal investigator for the DAGIS study and designed this research together with PH. PH was responsible for data analysis and drafted the manuscript, which was revised based on input from co-authors MHL, CR, SM, HV, LK, NS, ME, and ER. All authors approved the final version. 


\section{Funding}

This work was supported by Folkhälsan Research Center, University of Helsinki, The Ministry of Education and Culture in Finland, The Ministry of Social Affairs and Health, The Academy of Finland (Grants: 285439, 287288, 288038, 315816), The Juho Vainio Foundation, The Signe and Ane Gyllenberg Foundation, The Finnish Cultural Foundation/South Ostrobothnia Regional Fund, The Päivikki and Sakari Sohlberg Foundation, Medicinska Föreningen Liv och Hälsa, Finnish Foundation for Nutrition Research, and Finnish Food Research Foundation.

\section{Ethics declarations}

The University of Helsinki Ethical Review Board in the Humanities and Social and Behavioral Sciences has reviewed Eva Roos's, Maijaliisa Erkkola's, and Nina Sajaniemi’s study “DAGIS - Terveyden ja hyvinvoinnin edistäminen päiväkodeissa" in the board meeting on February 24, 2015. The review board finds that, based on the received material, the planned study follows the ethical principles of research in the humanities and social and behavioral sciences issued by the Finnish Advisory Board on Research Integrity. Thus, the review board stated that the mentioned study is ethically acceptable.

\section{Competing interests}

The authors declare that they have no competing interests. 
References

Belmon, L. S., van Stralen, M. M., Busch, V., Harmsen, I. A., \& Chinapaw, M. J. M. (2019). What are the determinants of children's sleep behavior? A systematic review of longitudinal studies. Sleep Medicine Reviews, 43, 60-70. doi:10.1016/j.smrv.2018.09.007

Beyens, I., \& Nathanson, A. I. (2019). Electronic media use and sleep among preschoolers: Evidence for timeshifted and less consolidated sleep. Health Communication, 34(5), 537-544. doi:10.1080/10410236.2017.1422102

Brockmann, P. E., Diaz, B., Damiani, F., Villarroel, L., Núñez, F., \& Bruni, O. (2015). Impact of television on the quality of sleep in preschool children. Sleep Medicine, 20, 140-144. doi:10.1016/j.sleep.2015.06.005

Cain, N., Gradisar, M. (2010). Electronic media use and sleep in school-aged children and adolescents: a review. Sleep Med, 11, 735-42. https://doi.org/10.1016/j.sleep.2010.02.006

Carson, V., Kuzik, N., Hunter, S., Wiebe, S. A., Spence, J. C., Friedman, A. \& Hinkley, T. (2015). Systematic review of sedentary behavior and cognitive development in early childhood. Preventive Medicine, 78, 115-122. doi:10.1016/j.ypmed.2015.07.016

Dahl, R. (2007) Sleep and the developing brain. Commentary on Touchette et al, Associations between sleep duration patterns and behavioral/cognitive functioning at school entry. Sleep, 30(9), 1213-19. doi: $10.1093 /$ sleep/30.9.1213

Dubois-Comtois, K., Pennestri, M. H., Bernier, A., Cyr, C., \& Godbout, R. (2019). Family environment and preschoolers' sleep: The complementary role of both parents. Sleep Medicine, 58, 114-122. doi:S13899457(19)30064-4

Engberg, E., Figueiredo, R. A. O., Rounge, T. B., Weiderpass, E., \& Viljakainen, H. (2019). Heavy screen users are the heaviest among 10,000 children. Scientific Reports, 9(1), 11158-9. doi:10.1038/s41598019-46971-6

Exelmans, L., \& Van den Bulck, J. (2019). Sleep research: A primer for media scholars. Health Communication, 34(5), 519-528. doi:10.1080/10410236.2017.1422100

Fukuda, K., Hasegawa, T., Kawahashi, I., \& Imada, S. (2019). Preschool children's eating and sleeping habits: Late rising and brunch on weekends is related to several physical and mental symptoms. Sleep Medicine, 61, 73-81. doi:10.1016/j.sleep.2019.03.023

Garrison, M. M., Liekweg, K., \& Christakis, D. A. (2011). Media use and child sleep: The impact of content, timing, and environment. Pediatrics, 128(1), 29-35. doi:10.1542/peds.2010-3304

Genuneit, J., Brockmann, P. E., Schlarb, A. A., \& Rothenbacher, D. (2018). Media consumption and sleep quality in early childhood: Results from the ulm SPATZ health study. Sleep Medicine, 45, 7-10. doi:10.1016/j.sleep.2017.10.013

Goodlin-Jones, B. L., Sitnick, S. L., Tang, K., Liu, J., \& Anders, T. F. (2008). The children's sleep habits questionnaire in toddlers and preschool children. Journal of Developmental \& Behavioral Pediatrics, 29(2), 82-88. doi:10.1097/DBP.0b013e318163c39a

Hale, L., \& Guan, S. (2015). Screen time and sleep among school-aged children and adolescents: A systematic literature review. Sleep Medicine reviews, 21, 50-58. doi:https://doi.org/10.1016/j.smrv.2014.07.007 
Hauri, P. \& Fisher, J. (1986). Persistent psychophysiologic (learned) insomnia. Sleep, 9, 38-53. https://doi.org/10.1093/sleep/9.1.38

Hense, S., Barba, G., Pohlabeln, H., De Henauw, S., Marild, S., Molnar, D. \& Ahrens, W. (2011). Factors that influence weekday sleep duration in european children. Sleep, 34(5), 633-639. doi:10.1093/sleep/34.5.633

Hinkley, T., Teychenne, M., Downing, K. L., Ball, K., Salmon, J., \& Hesketh, K. D. (2014). Early childhood physical activity, sedentary behaviors and psychosocial well-being: A systematic review. Preventive Medicine, 62, 182-192. doi:https://doi-org.libproxy.helsinki.fi/10.1016/j.ypmed.2014.02.007

Kabali, H. K., Irigoyen, M. M., Nunez-Davis, R., Budacki, J. G., Mohanty, S. H., Leister, K. P., \& Bonner, J., Robert L. (2015). Exposure and use of mobile media devices by young children. Pediatrics, 136(6), 1044-1050. doi:10.1542/peds.2015-2151

Lauricella, A. R., Wartella, E., \& Rideout, V. J. (2015). Young children's screen time: The complex role of parent and child factors. Journal of Applied Developmental Psychology, 36, 11-17. doi:https://doi.org/10.1016/j.appdev.2014.12.001

LeBlanc, A. G., Spence, J. C., Carson, V., Connor Gorber, S., Dillman, C., Janssen, I. \& Tremblay, M. S. (2012). Systematic review of sedentary behaviour and health indicators in the early years (aged 0-4 years). Canadian Science Publishing. 37(4):753-72. doi:10.1139/h2012-063

Lehto, E., Ray, C., Vepsäläinen, H., Korkalo, L., Lehto, R., Kaukonen, R., . . Roos, E. (2018). Increased health and wellbeing in preschools (DAGIS) Study_Differences in children's energy balance-related behaviors (EBRBs) and in long-term stress by parental educational level. International Journal of Environmental Research and Public Health, 15(10), 2313. doi:10.3390/ijerph15102313

Leppänen, M., Ray, C., Wennman, H., Alexandrou, C., Sääksjärvi, K., Koivusilta, L., Erkkola, M. \& Roos, E. (2019). Compliance with the 24-h movement guidelines and the relationship with anthropometry in Finnish preschoolers: the DAGIS study. BMC Public Health. Dec 3;19(1):1618. https://doi.org/10.1186/s12889-019-7967-7

Miller, A. L., Lumeng, J. C., \& LeBourgeois, M. K. (2015). Sleep patterns and obesity in childhood. Current Opinion in Endocrinology, Diabetes, and Obesity, 22(1), 41-47. doi:10.1097/MED.0000000000000125

Moorman, J., Morgan, P., \& Adams, T. (2019). The implications of screen media use for the sleep behavior of children ages 0-5: A systematic review of the literature. Current Sleep Medicine Reports, 5(3), 164172. doi:10.1007/s40675-019-00151-0

Määttä, S., Lehto, R., Nislin, M., Ray, C., Erkkola, M., Sajaniemi, N., \& Roos, E. (2015). Increased health and well-being in preschools (DAGIS): Rationale and design for a randomized controlled trial. BioMed Central. 15(1):402. doi:10.1186/s12889-015-1744-Z

Paavonen, E., Pennonen, M., Roine, M., Valkonen, S., Lahikainen, A. (2006), TV exposure associated with sleep disturbances in 5- to 6-year-old children. J Sleep Res., (15), 154-161. doi: 10.1111/j.13652869.2006.00525.x

Przybylski, A. K. (2019). Digital screen time and pediatric sleep: Evidence from a preregistered cohort study. The Journal of Pediatrics, 205, 218-223.e1. doi:10.1016/j.jpeds.2018.09.054 
Robinson, T. N., Banda, J. A., Hale, L., Lu, A. S., Fleming-Milici, F., Calvert, S. L., \& Wartella, E. (2017). Screen media exposure and obesity in children and adolescents. Pediatrics, 140(2), 97-101. doi:10.1542/peds.2016-1758K

Séguin, D., \& Klimek, V. (2016). Just five more minutes please: Electronic media use, sleep and behaviour in young children. Early Child Development and Care, 186(6), 981-1000. doi:10.1080/03004430.2015.1071528

Tang, L., Darlington, G., Ma, D. W. L., \& Haines, J. (2018). Mothers' and fathers' media parenting practices associated with young children's screen-time: A cross-sectional study. BMC Obesity, 5(1), 1-10. doi:10.1186/s40608-018-0214-4

Thomee, S., Dellve, L., Harenstam, A. (2010). Perceived connections between information and communication technology use and mental symptoms among young adults - a qualitative study. BMC Public Health, 10:66. doi: 10.1186/1471-2458-10-66

Vandewater, E. A., Bickham, D. S., Lee, J. H., Cummings, H. M., Wartella, E. A. and Rideout. (2005). When the television is always On - Heavy television exposure and young children's development. American Behavioral Scientist, 48: 562- 577. doi:10.1177/0002764204271496

Wen, L., M., van der Ploeg, H., Kite, J., Cashmore, A. \& Rissel, C. (2010). A Validation Study of Assessing Physical Activity and Sedentary Behavior in Children Aged 3 to 5 Years. Pediatric exercise science. 22. 408-20. 10.1123/pes.22.3.408. doi: 10.1123/pes.22.3.408

Wu, X., Tao, S., Rutayisire, E., Chen, Y., Huang, K., \& Tao, F. (2017). The relationship between screen time, nighttime sleep duration, and behavioural problems in preschool children in china. European Child \& Adolescent Psychiatry, (26), 541-548. doi: 10.1007/s00787-016-0912-8 
